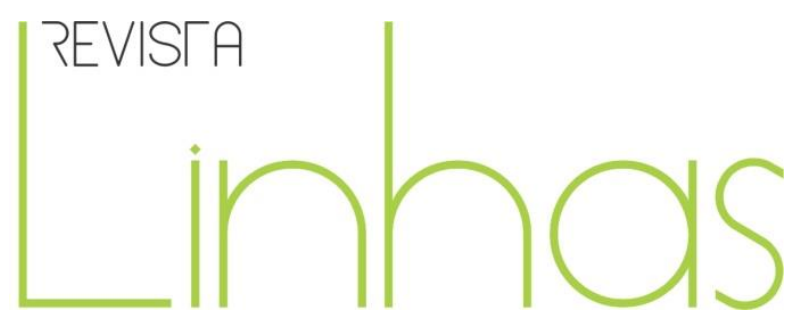

\title{
"No meu tempo, [...] haveria um respeito ao sexo e ao gênero das pessoas": Reiterações das normas de gênero e da heteronormatividade no currículo escolar
}

\begin{abstract}
Resumo
Este artigo traz parte dos resultados de uma pesquisa de mestrado em Educação que analisou os processos de (re)produção de sujeitos generificados em uma escola pública de Educação Básica, localizada em Aracaju (SE). Esta pesquisa foi elaborada sob a perspectiva póscrítica educacional entre os anos 2015 e 2017. Como metodologia, articulamos entrevistas semiestruturadas e análise do discurso e problematização de inspiração foucaultiana. Para produção de informações, utilizamos entrevistas com perguntas semiestruturada com 16 docentes ( 12 mulheres e 4 homens), com idade entre 27 e 66 anos. Foi possível perceber que as normas de gênero, em articulação com a heternormatividade, estão presentes na escola investigada a partir de discursos científico, biológico e religioso que, por sua vez, estabelecem dicotomias, vinculações e resistências caracterizando gênero como algo em constante produção e (re)produção. Considerando que problematização é um convite para colocar sob suspeita nossas formas de pensar e agir, mobilizamos, pois, os excertos das entrevistas como um aceite a esse convite e como um modo de tensionar esses discursos.
\end{abstract}

Palavras-chave: Gênero. Escola. Pós-crítica. Heteronormatividade.
Danilo Araujo de Oliveira

Universidade Federal de Minas

Gerais - UFMG - Belo Horizonte/MG

- Brasil

danilodinamarques@hotmail.com

\section{Anderson Ferrari}

Universidade Federal de Juiz de Fora - UFJF - Juiz de Fora/MG Brasil

aferrari13@globo.com

\section{Para citar este artigo:}

OLIVEIRA, Danilo Araujo de; FERRARI, Anderson. "No meu tempo, [...] haveria um respeito ao sexo e ao gênero das pessoas": Reiterações das normas de gênero e da heteronormatividade no currículo escolar. Revista Linhas. Florianópolis, v. 22, n. 48, p. 194-220, jan./abr. 2021. 


\title{
"In my time, $[. .$.$] there would be$ respect for people's sex and gender": Reiterations of gender norms and heteronormativity in the school curriculum
}

\begin{abstract}
This article brings part of the results of a Master's in Education research that analyzed the processes of (re) production of gendered subjects in a public school of Basic Education, located in Aracaju (SE). This research was carried out from a post-critical educational perspective between the years 2015 and 2017. As a methodology, we articulated semi-structured interviews and discourse analysis and problematization of Foucault inspiration. For information production, we used interviews with semistructured questions with 16 teachers ( 12 women and 4 men), aged between 27 and 66 years. It was possible to perceive that gender norms, in conjunction with heternormativity, are present in the investigated school from scientific, biological and religious discourses that, in turn, establish dichotomies, links and resistances characterizing gender as something in constant production and (re)production. Considering that problematization is an invitation to put our ways of thinking and acting under suspicion, we therefore mobilize the excerpts of the interviews as an acceptance of this invitation and as a way to tension these discourses.
\end{abstract}

Keywords: Gender. School. Post-criticism. Heteronormativity. 
Don't be normal. Era essa frase que, curiosa e provocativamente, estampava a blusa de uma professora de Inglês (59 anos), de uma escola pública, durante a entrevista para a pesquisa que originou este artigo. Uma frase escrita em letras garrafais e coloridas. Sua tradução pode ser considerada uma sugestão: “não seja normal”. Uma frase numa blusa e uma ação que nos convidam a pensar que o corpo pode ser entendido como um local de escrita. O que escolhemos para vestir, para informar e para mostrar aos outros diz das nossas relações conosco mesmos, com o que acreditamos e com aquilo que queremos transmitir.

Dessa forma, podemos pensar que aquela frase numa camisa e num contexto de entrevista para uma pesquisa em gênero e sexualidade era um convite. O convite que estava sendo feito pela frase e, portanto, pelo corpo da professora, era de subversão, já que a frase destoa de uma infinidade de outros artefatos culturais ${ }^{1}$ que interpelam para que as pessoas assumam a postura do que é tido como normal, para que se enquadrem e se aproximem de um modelo e de um ideal valorizado socialmente. O convite parecia dizer: discorde do normal, questione o enquadramento, permita-se, não se encaixe, (re)crie. Não ser normal soava como positivo e parecia afirmar um direito às pessoas de serem "estranhas", de não se convencerem por discursos que tentam dizer a maneira correta e/ou adequada de se comportar, de se identificar, de se perceber.

Essa é a discussão que se pretende aqui, ou seja, as relações de construção e problematização do que é considerado normal e anormal nas relações de gênero e sexualidade e como a escola participa desse jogo de poder-saber e da verdade do sujeito. Estamos partindo do pressuposto de que a escola funciona como um local privilegiado de normalização (MISKOLCI, 2012), mas também como local de resistência. Tomando como inspiração os estudos de Michel Foucault (2014a), podemos dizer que o modelo de escola que temos é herdeiro de um investimento numa sociedade disciplinar, atravessada por relações de poder. Mas, trabalhando com as relações de poder para problematizar os modos de constituição dos sujeitos, o filósofo vai afirmar "que se não há resistência, não

\footnotetext{
${ }^{1}$ Segundo Andrade e Costa (2015), o conceito de artefato cultural dialoga com as pedagogias culturais. $O$ artefato cultural não apenas reproduz, mas também produz saberes e sujeitos. Com isso, queremos dizer que o pedagógico ocorre em outros espaços que não sejam a educação formal.
} 
há relações de poder. Porque tudo seria uma questão de obediência" (FOUCAULT, 2014b, p. 257). O uniforme, as filas, os horários a serem obedecidos, a distribuição dos espaços, a separação constante, por sexo, nos banheiros, nas brincadeiras, nas atividades pedagógicas, tudo isso funciona como uma maquinaria para produzir sujeitos normalizados, ou melhor, para produzir homens e mulheres "de verdade". Um investimento que não é garantia de sucesso e de obediência. As resistências, as transgressões e as liberdades dos sujeitos estão presentes. Resistir não significa dizer simplesmente "não". "Dizer não constitui a forma mínima de resistência. Mas, naturalmente, em alguns momentos, é muito importante. É preciso dizer não e fazer deste não uma forma decisiva de resistência" (FOUCAULT, 2014b, p. 257). E, quando isso acontece, como a escola se manifesta?

É possível dizer que, mediante métodos reiterativos que não são questionados, devido à sua aparente naturalidade, são interiorizados os saberes de um regime de normalidade, por meio do qual os corpos deverão se conformar e (re)produzir incessantemente seus saberes, vigiar a si mesmos e aos outros. Nesse processo, o regime de heteronormatividade entra em cena e produz "verdades" que dizem de uma sexualidade regular e normal - a heterossexualidade - e de modos adequados de masculinidade e feminilidade conferidos aos corpos. Assim, heteronormatividade será entendida aqui como "um conjunto de disposições (discursos, valores, práticas etc.) por meio dos quais a heterossexualidade é instituída e vivenciada como única possibilidade legítima de expressão sexual e de gênero" (JUNQUEIRA, 2010, p. 212). Valendo-se desses discursos, valores e práticas, as demandas educativas também conferem inteligibilidade de gênero aos corpos que se conformam ou se aproximam de seus ideais, marcam e regulam aqueles que apresentam performances que destoam, distanciam e rompem com seus saberes.

Considerando os referenciais teóricos da vertente pós-crítica (BRITZMAN, 1996; BUTLER, 2003; FOUCAULT, 2014a, 2014b, 2014C; LOURO, 2015; SILVA, 1999), que têm sido mobilizados para desconstrução e questionamento do conhecimento humano sobre corpo, gênero e sexualidade na escola e em diversos espaços educativos, realizamos uma pesquisa, entre os anos 2015 e 2017, que tinha como objetivo geral a identificação e a análise do funcionamento e atuação das normas de gênero e da heteronormatividade em 
uma escola de Educação Básica em Aracaju (SE)². Nesta pesquisa, duas questões norteadoras constituíam o foco central para a análise: Como as normas de gênero estão funcionando na escola investigada? Como a heteronormatividade atua nessa escola?

A pesquisa aconteceu em um colégio público de Aracaju (SE). A unidade de ensino oferece turmas do $6^{\circ}$ ano do Ensino Fundamental ao $3^{\circ}$ ano do Ensino Médio, nos turnos matutino e vespertino, com 416 alunos e alunas, 18 professores e professoras, duas coordenadoras e uma diretora. Após o contato com a escola, que aceitou o trabalho com as temáticas de corpo, gênero e sexualidade, assumimos a observação e as entrevistas semiestruturadas como procedimentos metodológicos. No que se refere à observação, destacamos que ela ocorreu nos espaços escolares, tais como sala de aula, recreio, entrada e saída dos alunos e alunas, enfim, locais em que observávamos os comportamentos, os diálogos, as expressões corporais para problematizar os jogos de construção dos gêneros e sexualidades. Para as entrevistas semiestruturadas, organizamos algumas questões norteadoras, mas investimos mais no diálogo. Elas foram realizadas com dez professoras, quatro professores e duas coordenadoras no sentido de perceber as situações sob outra perspectiva, provocando o incômodo capaz de problematizar a escola e seus saberes, que estão presentes nas relações com alunos e alunas. No recorte que fazemos para este artigo, trazemos excertos das entrevistas de algumas professoras e um professor. São elas: Aline, professora de Biologia; Daniela, professora de Língua Portuguesa; Maria, professora de Língua Inglesa e Paulo³, professor de Geografia.

Para as análises, mobilizamos elementos da análise do discurso de inspiração em Michel Foucault (2014a), e problematização do mesmo autor. O discurso é entendido como uma prática produtiva de poder-saber. Inserida no campo da análise do discurso, partimos da compreensão de que "não se pode falar qualquer coisa em qualquer época" (FISCHER, 2001, p. 221). Desse modo, essa abordagem trouxe a possibilidade de perguntar: "por que isso é dito aqui, desse modo, nesta situação, e não em outro tempo e lugar, de forma diferente?" (FISCHER, 2001, p. 205). A problematização, por sua vez, é a perspectiva que norteou os estudos de Michel Foucault (2010), como uma forma de fazer

\footnotetext{
2 Este texto é, portanto, uma adaptação da dissertação de mestrado do autor Danilo Araujo de Oliveira. Para acesso ao referido texto, ver: OLIVEIRA (2017).

${ }^{3}$ A fim de manter o anonimato dos sujeitos, todos os nomes usados são fictícios.
} 
pesquisa para colocar sob suspeita nossas maneiras de pensar, de agir e de ser. Assim, a problematização não é apenas um conceito, mas uma possibilidade de fazer pesquisa. $\mathrm{Na}$ contramão de um currículo normatizador, a problematização contribuiria mais para o entendimento de um cotidiano plural, inclusivo e que viabilizasse a valorização dos direitos humanos, percebendo que há uma construção histórica que prioriza um padrão heteronormativo e discursos de poder que entrelaçam o currículo escolar. Assumir esse entendimento significa colocar em suspensão, em dúvida, esse conhecimento instituído, que muitas vezes se apresenta por meio dos discursos biológico, médico, psicológico, social, religioso e político, que podem engessar o currículo em prol de um discurso binarista.

Discurso binarista é entendido aqui como uma prática sociocultural dos gêneros que os estrutura e os apresenta de maneira binária, isto é, "tendo como possibilidades o masculino e o feminino" (REIS, PINHO, 2016, p. 11). Conforme destacam Reis e Pinho (2016, p. 11) “essa forma de construção advém de um suposto determinismo biológico, no qual os corpos são entendidos no dimorfismo macho-fêmea". Nesse sentido, o autor e a autora ainda afirmam que masculino e feminino são construídos numa relação oposicional, representados anatomicamente de maneira estável e com papéis socialmente delimitados. De maneira que "ser homem implica em não ser mulher, em rejeitar todo e qualquer marcador identitário inscrito no universo feminino" (REIS, PINHO, 2016, p. 11).

Na contramão desse engessamento do currículo, a problematização é uma forma de promover discussões para inquietar o que já é cômodo fazer, que é reproduzir essas normas em vez de desconstruir e propor novas formas de conhecer e significar a diversidade, os corpos estranhos, a multiplicidade de identidades que povoam e que podem abalar a centralidade de uma pedagogia unilateral. É numa perspectiva de questionamento, portanto, que este artigo se move, uma vez que ele parte da inquietação, do abandono dos opostos, da zona de conforto que as respostas prontas colocaram para assumir uma postura de risco.

Dessa forma, entendemos que o cotidiano escolar é também currículo e age investindo e subjetivando os corpos que ali estão. Feitas essas colocações introdutórias, organizamos este texto em duas partes. Uma primeira em que o foco é problematizar, 
conceitualmente, como as normas de gênero estão funcionando na escola, para, em seguida, concentrar nossa escrita numa segunda parte em que o campo empírico aparece para questionarmos como a heteronormatividade atua no currículo que encontramos na escola investigada.

\section{Normas de gênero e escola}

Inicialmente, reconhecemos que pesquisas como esta que realizamos só são possíveis em função da construção e da consolidação de uma área do conhecimento intitulada Gênero, Sexualidade e Educação. Com isso, queremos nos filiar como tributários a essa produção de conhecimento que antecedeu e norteou nossos caminhos de pesquisa e suas análises. Portanto, nesta primeira parte do artigo, vamos recuperar e buscar dialogar com esse arcabouço teórico da área. Para começar esse diálogo, uma das primeiras ideias que queremos problematizar diz da constituição do gênero e de suas relações com os sujeitos. As características atribuídas aos homens e às mulheres fazem parte de um processo histórico de construção que engendram nos corpos modos de existir de forma binária, concebendo os sujeitos a partir do sexo.

Afirmar essa construção inicial dos gêneros não significa que encerramos o debate nesse tipo de enquadramento e que estamos tomando essas constituições como essência. Considerando o seu caráter de construção, queremos colocar sob suspeita essa forma de construir e entender os gêneros, defendendo que corpos e sujeitos não se limitam ao binarismo de gênero, visto que outras formas de vida podem e são dignas de serem vividas na inventividade dos sujeitos e suas relações com os corpos, com os saberes, com os outros, com os desejos e com a vida.

Assim, gênero pode ser compreendido como "o caráter fundamentalmente social das distinções baseadas no sexo" (SCOTT, 1995, p. 72). É no social que os gêneros adquirem inteligibilidade e que são construídas as diferenças e as oposições entre homem e mulher. O binarismo homem/mulher, pautado no aspecto biológico, foi construído e disseminado nas relações sociais. Modos de vestir, de se comportar, de agir e pensar são determinados para homens e mulheres de formas diferentes, que, por meio de discursos repetidos e reiterados, naturalizam posições e fixam os corpos de forma polarizada, em 
que, de um lado, está uma forma legitimada de ser homem e, do outro, de ser mulher. Buscando a pluralização do gênero, os estudos pós-estruturalistas ampliam a concepção de gênero sugerindo pensar as múltiplas formas de masculinidade e feminilidade que os corpos podem representar, no binarismo de gênero e para além desse enquadramento. As diferenças entre as sociedades e no interior de cada sociedade, nos seus diferentes momentos históricos, demonstram a necessidade de evitarmos a generalização do que se pode compreender por “homem” e por “mulher”. Guacira Lopes Louro (2003) é uma das autoras de referência no Brasil na construção do conceito de gênero e sua vinculação com processos educativos.

Afasta-se (ou se tem a intenção de afastar) proposições essencialistas sobre os gêneros: a ótica está dirigida a um processo, para uma construção, e não para algo que exista a priori. O conceito passa a exigir que se pense de modo plural, acentuando que os projetos e representações sobre mulheres e homens são diversos. (LOURO, 2003, p. 23)

A vertente pós-estruturalista, nos seus diálogos com os estudos feministas, permitiu problematizar o binarismo de gênero, de maneira que "a noção estável de gênero dá mostras de não mais servir como premissa básica da política feminista, talvez um novo tipo de política feminista seja agora desejável para contestar as próprias reificações de gênero" (BUTLER, 2003, p. 23). As feministas foram as primeiras a denunciar o aspecto de construção relacional dos gêneros, assim como seu teor disciplinador.

Foucault (2014a) nos convida a pensar como fomos nos tornando uma sociedade disciplinar, ou seja, como investimos insistentemente em procedimentos que visam disciplinar os sujeitos e seus corpos em prol de uma sociedade produtiva. Podemos acrescentar que, além de uma sociedade disciplinar ou como parte dela, também somos uma sociedade do enquadramento. Somos ensinados e aprendemos a enquadrar a nós mesmos e os sujeitos, atribuindo sentidos aos seus corpos, aos desejos, às formas de ser e estar no mundo. Nesses processos de disciplinamento e enquadramento, a sociedade busca constantemente capturar os corpos para que eles se encaixem, se adequem, tornem-se homem ou mulher como o desejado, visto que "gênero não é algo que se 
'deduz de um corpo'. Não é natural. Em vez disso, é a própria designação como macho ou como fêmea, como masculino ou feminino que 'faz' esse corpo” (LOURO, 2016, p. 13).

O gênero se constrói a partir de discursos, que dizem quais são as formas "verdadeiras" que constituem as pessoas na sua condição de sujeitos; que dão uma referência, um padrão que é indicado a ser seguido, e que servem para regular os sujeitos. Nessa constituição, os corpos escapam, transgridem, denunciam a naturalidade e evidenciam a fabricação do que é posto como verdadeiro. Com isso, queremos afirmar nosso argumento de que os gêneros não podem ser entendidos como essências e naturais, algo dado, mas, sim, no jogo do verdadeiro e falso que está organizando os saberes sobre sujeitos, seus corpos, seus desejos e seus gêneros e sexualidades. Os corpos e os sujeitos são resultado e efeito da verdade de um discurso sobre a identidade primária e estável, como nos lembra Judith Butler (2003).

Em consonância com esse pensamento, passamos, então, a compreender gênero como norma, não sendo norma entendida como regra ou lei, mas como "uma medida e um meio de produzir um padrão comum" (BUTLER, 2014, p. 264), o que implica afirmar que sua atuação perpassa por relações de poder que pretendem produzir sujeitos específicos. Assim “ela está sempre ligada a uma técnica positiva de intervenção e de transformação, a uma espécie de poder normativo" (FOUCAULT, 2001, p. 21). Dessa maneira, a norma se configura como "um elemento a partir do qual certo exercício de poder se acha fundado e legitimado" (FOUCAULT, 2001, p. 62).

Ao dizer que existem normas de gênero, entendemos que elas produzem, fabricam, criam e inventam corpos generificados. Mais do que isso, que essas normas são construções discursivas que tomam forma nas relações dos sujeitos com os saberes, com o social e com o histórico. Dizer do outro, enquadrar e disciplinar o outro é, ao mesmo tempo, dizer de nós e construir a nós mesmos. Essas relações entre sujeitos na constituição e dinâmica das normas se dá no interior das instituições, como a escola, por exemplo, que é a instituição que nos interessa aqui para pensar sua ação nesse jogo de produção e (re)produção dos sujeitos. A escola faz parte dessa sociedade que disciplina e enquadra, ela é uma instituição de sequestro ${ }^{4}$, como nos provoca a pensar Foucault

\footnotetext{
${ }^{4} \mathrm{Na}$ sua trajetória de investigação, Michel Foucault se dedicou a responder à questão: "como nos tornamos o que somos?". Uma questão interessada nos modos de subjetivação. Para isso, ele vai se dedicar a pensar o sujeito em meio à constituição de uma sociedade moderna marcadamente como disciplinar, aquela que investe em processos de disciplinar os sujeitos e seus corpos pelas instituições, chamadas de "instituições
} 
(2014a), quando vai olhar para os mecanismos e instituições que participam da construção dessa sociedade disciplinar moderna.

A escola não é a única instituição responsável por disciplinar os sujeitos nas suas relações com as construções de gênero. As normas de gênero circulam em diversas instituições e constroem 'verdades' sobre os modos de ser homem e mulher, instituindo um "conjunto de medidas que visam corrigir o indivíduo, exercendo sobre ele uma série de diagnósticos e padrões a serem seguidos e estratégias para normalizar suas ações" (RIBEIRO, 2014, p. 126). Estamos trabalhando o tempo todo com o entendimento do gênero como produção discursiva e, com isso, queremos reafirmar que ele - gênero - é atravessado por saberes e relações de poder. Ele é resultado de disputa política, que envolve as instituições nos seus investimentos nos sujeitos e nas suas próprias existências vinculadas aos saberes que os constituem.

Desse modo, a escola se faz em meio a discursos sobre gêneros acionando saberes com o status de científico. Mas os gêneros não estão presentes nas escolas somente por aquilo que os professores e professoras fazem, dizem, trabalham. Eles também chegam trazidos pelos alunos e alunas, com suas inventividades e formas de ser e estar no mundo, como saberes aprendidos na família, na religião, no grupo de amigos e amigas, enfim, como resultado de saberes daquilo que foi aprendido pela produção discursiva de outras instituições. Por meio de uma atualização de discursos, reiteração constante de atos, promoção de enunciações, são produzidos artefatos culturais ${ }^{5}$ e tecnologias que trabalham a serviço de um modelo de sociedade que traça as fronteiras entre o normal e o anormal.

Se a escola produz saberes e discursos sobre as relações de gênero, as famílias também produzem, as igrejas fazem o mesmo, assim como as mídias, enfim, diferentes instituições disputam os gêneros e seus embaralhamentos com as sexualidades. Disputam porque nem sempre concordam. Muitas vezes as instituições discordam, atacam, desqualificam, perseguem e concorrem para se afirmarem como donas de um saber sobre gênero que enquadre as demais.

de sequestro". Essas instituições são aquelas em que somos obrigados a participar para que o projeto moderno de produtividade do sujeito se realize, dentre elas, está a escola.

${ }^{5}$ Artefatos culturais como, por exemplo, a internet, a televisão, o cinema, os jornais, a literatura, o rádio, os brinquedos, as músicas etc. 
Dessa forma, são as articulações empreendidas pela escola, suas manobras, as táticas e as técnicas que colocam em funcionamento para enquadrar, atingir o sujeito, torná-lo como se quer, como se julga 'correto' que nos interessa para pensar os desafios e as potencialidades da educação na constituição dos sujeitos. Uma pessoa vai se constituindo e constituindo o outro também, por meio dos saberes alcançados que se prestam a julgar 'normais' ou 'anormais', negociando formas de existir e resistir. A partir de minúcias, da organização dos espaços, da arquitetura escolar, dos horários, o currículo expressa seus desejos e saberes; a partir dele, aprende-se quem se é, quais procedimentos são 'corretos' e o que se podem tornar. Efetivamente, as pessoas se constituem pelos discursos que estão em outras instituições e também na escola e dizem quem cada um é, como resultado dos dispositivos que vão nos constituindo como somos (SILVA, 1999). Na obra História da Sexualidade I, Foucault define o dispositivo como

\footnotetext{
um conjunto decididamente heterogêneo que engloba discursos, instituições, organizações arquitetônicas, decisões regulamentares, leis, medidas administrativas, enunciados científicos, proposições filosóficas, morais, filantrópicas. Em suma, o dito e o não dito são os elementos do dispositivo. O dispositivo é a rede que se pode tecer entre estes elementos. (FOUCAULT, 2014a, p. 244)
}

Como a sexualidade, queremos tomar o conceito de dispositivo para pensar o gênero como parte dessa rede que constitui sujeitos. A sexualidade como um dispositivo de constituição dos sujeitos ocorre por uma rede que também vai construindo o espaço escolar. Mais do que relação, temos um certo embaralhamento entre sexualidade e gênero. Para construir o gênero, acionamos a sexualidade, ou seja, ser homem está diretamente ligado a ser heterossexual. Muitas vezes as homossexualidades representam uma expulsão ao gênero, considerando que tal sujeito não é homem por ser homossexual, como se a homossexualidade constituísse um terceiro gênero. Com isso, queremos provocar o pensamento: os corpos, ao escaparem, podem ressignificar as noções de gênero ancoradas no biológico.

Ao instaurar "problemas" ao gênero e a essa articulação direta entre gênero e sexualidade, juntamente com os/as autores que aqui mobilizamos, estamos questionando o que foi historicamente instituído como 'natural', para evidenciar uma fabricação que é 
discursiva, pois, "ao nomear, ao instituir um padrão de classificação dos corpos, os discursos os formam continuamente e, também, oferecem a eles um sentido do que eles são, de como podem se situar culturalmente" (REIS; PARAíSO, 2014, p. 239).

Se os discursos interpelam, alcançam e penetram os corpos, mentes, fabricam e moldam pessoas, é necessário problematizar quais são os mais recorrentes, como agem, que verdades estão fazendo circular e quais os seus efeitos na produção, visibilidades e marginalização de saberes e sujeitos. Ao problematizar os discursos que ditam as normas de gênero, queremos duvidar dessa eficácia, colocando em questionamento os discursos que circulam exaustivamente para legitimar, autorizar e construir corpos em uma ordem dicotomizada, concebendo os lados masculino hegemônico e feminino subordinado e excluindo as expressões de gênero que não se enquadram nesses lugares. Se os gêneros são 'naturais', para que tanto investimento nessas relações binárias?

Nesse contexto, a escola pode ser ou atuar como campo disciplinador e normalizador, que constrói sujeitos com base em identidades gendradas, a partir dos discursos que ela elege como legítimos e das práticas discursivas que acontecem em seus espaços. Mas ela também pode ser um espaço de desconstrução e questionamento, pode tornar visíveis os sujeitos que estão em trânsito pelas identidades hegemônicas ou que se identificam fora delas. Estamos considerando que o papel que cabe às escolas está no campo das problematizações, nos moldes do pensamento foucaultiano, que significa investir na história do pensamento. O que pensamos e como agimos é resultado da história do pensamento. Nossos pensamentos e nossas ações têm história. Quando colocamos em dúvida o que pensamos (por que pensamos o que pensamos?) e, como agimos (por que ajo da forma que ajo?), estamos abrindo espaço para desconstruir, pensar e agir diferente do que temos feito até então. Para nós, o currículo está aberto e em constante construção.

Um currículo é um composto heterogêneo, constituído por matérias díspares e de naturezas distintas; por saberes diversos e com capacidades variadas; por sentidos múltiplos e com inúmeras possibilidades. Um currículo está sempre cheio de ordenamentos, de linhas fixas, de corpos organizados, de identidades majoritárias. Porém um currículo, também, está sempre cheio de possibilidades de rompimento das linhas do ser; de contágios que podem nascer e se mover por caminhos insuspeitados; de construção de modos de vida que 
podem se desenvolver de formas particulares. Um currículo é um artefato com muitas possibilidades de diálogos com a vida; com diversas possibilidades de modos de vida, de povos e de seus desejos. É um artefato com um mundo a explorar. Afinal, mesmo sendo um espaço disciplinar, por excelência, muitas coisas podem acontecer em um currículo. (PARAÍsO, 2009, p. 278)

Mais do que isso, o currículo tem um componente de imprevisibilidade e inventividade que não é possível controlar, por mais que os professores e as professoras insistam nisso. Os alunos e as alunas propõem um currículo o tempo todo, eles e elas dizem dos seus interesses, conflitos, curiosidades, desejos e, ao trazerem isso, estão nos mostrando como vão se constituindo em meio às suas formas de pensar e agir. Os gêneros, como organizadores sociais, estão presentes nessas relações entre alunos e alunas com os seus saberes e ações.

O princípio que os norteia é o da escola como local de subjetivação, onde se aprende o que se deve ou não fazer, onde vamos nos constituindo naquilo que somos. Os currículos trabalham sempre com duas questões: quem eu penso que os meus alunos e alunas são? Quem eu quero que eles e elas sejam? Como as normas de gênero buscam homogeneizar os indivíduos, muitas escolas silenciam as diferenças, contribuindo para reafirmação e atualização de discursos do que é um corpo generificado, buscando aproximar o máximo possível os corpos do que é desejável pela escola, corpos que estejam mais próximos dos padrões de masculinidade e feminilidade hegemônica. Agindo dessa forma, algumas escolas protegem as heterossexualidades como a norma.

Para procurar adequar corpos em uma norma e, ao mesmo tempo, classificar as anormalidades, diferenciados campos do saber são acionados para promover discursos de verdade. Então, aqueles corpos que se distanciam da referência são submetidos a práticas de normalização que se configuram, entre outras formas, por meio dos olhares e falas corrigindo posturas e gestos, demarcando espaços, colocando em filas, separando por sexo. Podemos dizer que há, na escola, uma série de mecanismos autorizados por um poder que designa o que é ‘normal’ e, que ao agir, também produz os “anormais”.

As técnicas que produzem os sujeitos na escola são detalhes que, para serem percebidos, precisam de um olhar mais atento, pois elas aparecem no currículo de forma naturalizada e sob um discurso de verdade que conferem à heterossexualidade a forma 
legítima de existir nesse espaço. A escola é parte de um conjunto de instituições sociais que se articulam na produção de gêneros inteligíveis. Dessa forma, ainda que, nesse espaço de sequestro, as normas de gênero sejam incessantemente reproduzidas, é necessário pensar na conjuntura em que ela está inserida como parte de um projeto social guiado por duas possibilidades excludentes, ou seja, no binarismo de gênero.

As pesquisas de Carvalhar (2010), Junqueira (2012) e Dornelles e Dal'igna (2015) também contribuem para a reflexão sobre as aprendizagens que acontecem de diferentes maneiras no espaço escolar, de forma persistente, para que os sujeitos se tornem "verdadeiramente" homens e mulheres. As condutas são vigiadas, há uma estimulação constante à incorporação das normas e sanções são aplicadas para inibir as transgressões. Por meio de mecanismos reincidentes, busca-se instaurar uma verdade quase absoluta e inquestionável. Ainda estamos presos a essa vontade da verdade do sujeito pela designação do gênero e dos desejos (FOUCAULT, 2014a). Essa busca pela verdade também está presente na escola, visto que ela toma os ensinamentos produzidos no seu interior, em diálogo com outros discursos que circulam na família e na mídia para a produção dos sujeitos, dos corpos aceitos e recusados, dos desejos permitidos e proibidos.

Contudo, as disputas, inerentes a esse processo, estão presentes nos corpos que transgridem as normas, nos docentes que trazem para o currículo conhecimentos que confrontam a produção da normalidade, nas pesquisas que propõem a desnaturalização de um sistema binário e traçam possibilidades para desestabilizar as certezas. Articulações que nos possibilitam "discutir formas potentes de inflexão da norma na configuração das margens e das rupturas possíveis com o plano normativo, ou seja, abrem-se brechas para se pensar na reversibilidade das marcas prescritivo-restritivas que atravessam essa instituição" (DORNELLES; DAL'IGNA, 2015, p. 1597).

Esse parece ser o desafio e a potencialidade da escola na atualidade; fortalecer-se nos sujeitos, suas existências e demandas, na produção de conhecimento da área do gênero, sexualidade e educação e na autonomia e liberdade dos professores e professoras na constituição de seus currículos e saberes. Então, não há referência a apenas um lugar no qual a norma se impõe sem encontrar resistência; os escapes têm anunciado outras possibilidades. 
Se as normas de gênero funcionam por meio de atos repetidos e reiterados por meio de discursos que legitimam modos de ser como verdadeiros, significa dizer que é preciso insistir também na promoção de discursos que proponham a sua desnaturalização, que denunciem sua arbitrariedade, que tornem suas verdades questionáveis. A escola, como um espaço de potência, lugar de produção do conhecimento, não reprodução do senso comum, pode viabilizar e discutir possibilidades e lugares que não os fixados pela norma, sugerir desconstruções do que está dado. Por isso, o conceito de normas de gênero é tão caro aqui, pois ele desafia suas imposições e perturba sua naturalidade. Feitos esses esclarecimentos a respeito da construção do conceito de gênero, o desafio é problematizar como ele faz circular esses saberes, práticas, discursos e sujeitos no cotidiano escolar.

\section{“Ele ou Ela?": o posicionamento dos corpos em lugares fixos e engendrados}

Inspirados nas perspectivas de gênero que analisamos anteriormente, fomos à escola para realizar 16 entrevistas semiestruturadas, entre os anos 2015 e 2017, criando um encontro entre a teoria e o campo empírico e, nesse encontro, produzindo conhecimento autoral sobre as produções de gênero no contexto escolar. Neste momento, recuperaremos a informação já apresentada na introdução de que vamos trabalhar com as narrativas de três professoras e um professor, que participaram das entrevistas semiestruturadas. Considerando as narrativas desse e dessas docentes, buscamos problematizar como as normas de gênero estão funcionando na escola investigada e como a heteronormatividade atua na relação entre saberes e sujeitos. Para isso, investigamos quais discursos estão atravessando as falas do e das docentes para legitimar as posições de sujeitos e evidenciada a ação do currículo como mecanismo de subjetivação a partir daquilo que ele elege e reitera como verdade.

Os corpos que transitam pelas fronteiras delimitadas pelas normas de gênero confundem, desestabilizam e questionam o modelo que é compulsoriamente ensinado como 'verdade' e como "única” forma de ser e estar no mundo. Quando esses corpos surgem, vários discursos são acionados para patologizá-los, anormalizá-los, reforçando um padrão heteronormativo. Diversas discussões têm sido empreendidas, possibilitando 
pensar as relações de poder que estão imbricadas no processo de produzir sujeitos normais (CARVALHAR, 2010; JUNQUEIRA, 2012; DORNELLES; DAL'IGNA, 2015). Pesquisas que demonstram que, ao atrelar as performances dos corpos subversivos aos gêneros, as sexualidades estão constantemente sendo desestabilizadas. Isso tem alcançado os mais diversos espaços, incluindo a escola. A partir da fala transcrita a seguir, percebemos que a docente reconhece outros discursos que embaralham suas construções interiorizadas sobre gênero:

Gênero é o que está se falando muito, é a questão de ser masculino ou feminino e hoje está procurando não diferenciar muito mais né? Essa questão, da sexualidade, né? Aí tá ficando um pouco confuso até, né? Mas... É isso. (ALINE, 2015. Informação verbal) ${ }^{6}$

A professora se utiliza de expressões temporais para marcar a atualidade da discussão, tais como "é o que está se falando muito" ou ainda "hoje está procurando não diferenciar". Essa atualidade e ênfase nas discussões têm seus efeitos. É inegável o avanço nas produções na área do gênero, sexualidade e educação. No entanto, podemos nos perguntar: como essa produção está chegando às escolas? Se está chegando, está servindo para problematizar os saberes que habitam esse espaço? A professora se refere a essa profusão de saberes como responsável por uma certa confusão. Não queremos tomar aqui o conceito de confusão como algo negativo. Gostaríamos de provocar o conceito no sentido de entender que a confusão é uma forma de tirar do confortável, do aceito, para levar ao processo de buscar outras formas de saber e olhar o mundo.

A classificação de que hoje está confuso se relaciona com uma certa procura por definição e por certezas, por algo mais seguro na articulação entre gênero e sexualidade. Percebemos que os enquadramentos não estão sendo sustentados com tanta eficácia. Um movimento que confunde, que mexe com as estruturas, que propõe a dúvida. A confusão também questiona o conhecimento, uma vez que parece que ela é causada pela identificação da falta de conhecimento que dê segurança. Não diferenciar masculino e feminino talvez esteja remetendo à ideia de desconstrução dos binarismos que perpassam pela educação, por entender que, independentemente de ser homem ou

\footnotetext{
${ }^{6}$ As falas das participantes estarão em itálico para diferenciar das citações.
} 
mulher, ora pode-se ser mais masculino, ora mais feminino, sem que isso esteja relacionado ao gênero ou à sexualidade. Para Louro,

a concepção dos gêneros como se produzindo dentro de uma lógica dicotômica implica um pólo que se contrapõe a outro (portanto uma ideia singular de masculinidade e de feminilidade), e isso supõe ignorar ou negar todos os sujeitos sociais que não se "enquadram" em uma dessas formas. (LOURO, 2003, p. 34)

Assim, a diferença entre ser homem e ser mulher, além de ser marcada por um órgão sexual, está atrelada a uma forma hegemônica de ser masculino e ser feminina. Dadas as construções interiorizadas que fixam os lugares e os modos de ser homem e ser mulher, as discussões que ampliam a maneira de entender gênero soam como confusão. Por isso, quando as dúvidas surgem, outros e outras docentes procuram responder acionando um discurso biológico sustentando que o gênero parte de um sexo anatômico, uma resposta que parece mais fácil de ser dada, mas que pode instaurar preconceitos e violência na escola. Seguindo essa lógica, como seria possível, por exemplo, entender o gênero das alunas travestis? Elas não poderiam ser percebidas como mulheres, já que existe em seus corpos um sexo anatômico que insiste em demarcar uma identidade de gênero masculino? Louro (2003, p. 32) considera que essa concepção "nos 'amarra' numa posição que é, aparentemente, consequente e inexorável. Uma lógica que parece apontar para um lugar 'natural' e fixo para cada gênero". Assim, gênero aparece como destino, de forma que é impossível transitar ou pensar em sua construção cultural. É esse discurso de naturalização que perpassa na narrativa abaixo:

Eu acredito que é uma opção que a pessoa faz, independe dessa opção individual a pessoa vai ter aquele gênero que está definido fisicamente nela. E eu, ainda, na minha cabeça, é opcional, a... a pessoa não se sente bem é, se ela for um homem ou uma mulher, mas ela opta por isso, mas é fisicamente existe gênero definido, marcado por um órgão sexual. (DANIELA, 2015. Informação verbal)

A noção de "opção" que aparece na narrativa remete à ideia de uma escolha consciente do indivíduo, no que se refere à sexualidade. Tal afirmação parece desconsiderar o caráter construtivo, social e cultural aos quais as pessoas são 
submetidas, (re)produzem e se transformam. Além disso, as certezas da definição de gênero são buscadas no "órgão sexual", de maneira que é a partir dele que se pode definir gênero, buscando-se a segurança do gênero. Uma coerência que, por certo, é buscada também pela professora Maria, quando ela afirma: "No meu tempo, eu ainda sou um pouco conservadora, haveria um respeito ao sexo e ao gênero das pessoas. Hoje não". A temporalidade volta a aparecer e parece demarcar um ontem seguro e um hoje confuso nos enquadramentos de gênero e sexualidade. Mais do que isso, a temporalidade parece ser demarcada por corpos e sujeitos que estão nas escolas e que, de certa forma, obrigam as professoras a estabelecerem essas relações entre o ontem e o hoje. Outro exemplo foi a fala da professora de Biologia da escola que contou que os alunos e as alunas perguntam a ela se existe uma relação entre genética e homossexualidade, ao que ela responde: “Aí, como é que se diz, vou mais pra parte biológica, né? Que essas questões genéticas ainda tá... Tem estudo, né? Têm alguns casos que já falam que sim, tem uma parte genética também" (ALINE, 2015. Informação verbal).

A professora Aline se pega à sua formação, ou seja, a um campo que ela domina e que, portanto, fornece segurança ao que vai dizer. Ela ainda insiste em marcar sua fala como ancorada em um saber reconhecido pela pesquisa: “tem estudo, né?” (ALINE, 2015. Informação verbal). A instituição “pesquisa”, “estudo”, “campo biológico” dá segurança à fala de Aline e, parece, autorizam-na a falar, colocando-se no regime de verdade, apontado por Foucault (2014a) para entender a sexualidade. Cada tempo constrói saberes e verdades sobre determinado conhecimento e esses regimes de verdade investem na constituição dos sujeitos. O discurso biológico atravessa as narrativas das professoras e também constrói o conhecimento dos alunos e alunas que buscam nele uma causa para a homossexualidade. Quando se questiona a escolha do discurso biológico para construir o conhecimento sobre sexualidade, interessa perceber, nessa dinâmica, "a vontade de saber que lhe serve ao mesmo tempo de suporte e instrumento" (FOUCAULT, 2014a, p. 17). Torna-se possível perceber, nos enunciados do discurso biológico, que sujeitos são produzidos por meio de suas "verdades", como elas são selecionadas, atualizadas e reiteradas para reforçar uma ordem dominante.

Quando os alunos e as alunas buscam uma relação entre genética e homossexualidade e perguntam isso à professora, é conferido um poder ao discurso 
biológico de dizer a verdade. É possível perceber nessa dinâmica que eles e elas não procuraram saber sobre a relação entre heterossexualidade e genética. Talvez, isso tenha acontecido, pois há um discurso científico naturalizado que diferencia homens e mulheres por meio da anatomia e da genética, estabelecendo dicotomias e reforçando uma heterossexualidade presumida para todos os corpos. O resultado sugerido é que as noções essencialistas são aprendidas sobre gênero e sexualidade.

A heterossexualidade talvez já seja entendida pela professora e pelos alunos e alunas por uma evidência biológica, de forma que eles e elas se construíram dentro do discurso que naturalizou a heterossexualidade por uma determinação biológica. A partir dessa determinação restritiva, sustenta-se a definição de macho e fêmea naturalizada, de gênero binário e de duas identidades possíveis e opostas.

Quando a professora Maria fala de um "respeito ao sexo e ao gênero", ela parece defender uma certa inteligibilidade entre corpo e gênero. Devido a esse modelo, nascer com um pênis significa que é homem e, então, uma série de expectativas são direcionadas para que esse corpo seja dócil, que ele incorpore as normas do que é ser homem dentro de um determinado discurso hegemônico, que ele mantenha performances "próprias" do seu sexo, modos de andar, vestir e se comportar são constantemente ensinados e, logo, o desejo pelo chamado sexo oposto também. Da mesma maneira, o corpo que nasce com uma vagina é educado conforme padrões que também são instituídos por essa lógica. Espera-se que as mulheres sejam submissas, tenham vocação para o lar, para o casamento e a maternidade.

Para Butler (2003, p. 24), "a hipótese de um sistema binário dos gêneros encerra implicitamente a crença numa relação mimética entre gênero e sexo, na qual o gênero reflete o sexo ou é por ele restrito". É uma crença que aparece no currículo oculto da Biologia, quando omite as possibilidades de descompasso entre gênero e sexo. Nascer com o sexo masculino não nos faz, necessariamente, masculino e homem. Essa mesma crença na relação mimética entre gênero e sexo também interpela outras realidades na intenção de capturar para corresponder a uma ordem dicotômica que pretende estabelecer critérios de normalidade e tornar os corpos que não correspondam às suas verdades, anormais (FOUCAULT, 2001) e marginalizados. 
A frase da professora Aline, ao trazer a afirmação que “independente dessa opção individual, a pessoa vai ter aquele gênero que está definido fisicamente nela [...]" (ALINE, 2015. Informação verbal) é atravessada por um discurso que naturaliza o gênero e a sexualidade. O órgão sexual funciona com uma espécie de autoridade. Assim, mesmo que as expressões de gêneros e sexualidades sejam dissonantes das verdades construídas em torno daquele sexo, o corpo continuará sendo nomeado por ele. Seguindo essa lógica, é possível afirmar que "aparentemente se deduz uma identidade de gênero, sexual ou étnica de 'marcas' biológicas; o processo é, no entanto, muito mais complexo, e essa dedução pode ser (e muitas vezes é) equivocada" (LOURO, 2015, p. 14). A concepção restritiva de gênero pode resultar em ações que subjetivam corpos como abjetos, estranhos, anormais:

A gente vai lidar com todo tipo de gente, olhe eu trabalhei ali [...] e eu achei interessante na época porque tinha um, um... ela se dizia professora, embora o nome fosse masculino, porque tem essa questão que veio liberar de você escolher há pouco tempo, então, esse rapaz, na verdade era um rapaz, ele passou num concurso para trabalhar em Itaporanga, concurso do Estado, e ele foi dar aula numa turma de $4^{\mathrm{a}}$ série na época e os alunos não aceitaram ele, porque ele é homem né? Só que ele ia travestido trabalhar. (PAULO, 2015. Informação verbal)

A confusão em usar o pronome "ela" ou “ele" marca a fala do professor Paulo. Há uma dificuldade em lidar com um corpo que constrói uma identidade diferente daquela que a biologia determina, visto que, mesmo se percebendo como mulher, havia o demarcador de um nome de registro masculino e o órgão biológico que conferia a ela o status de "verdadeiramente" homem: "esse rapaz, na verdade era um rapaz [...]", "[...] ele é homem né?" (PAULO, 2015. Informação verbal).

Paulo é o outro que marca a verdade do sujeito por uma parte do corpo que ele presume como originária dessa verdade e do gênero. No entanto, nem sempre quem eu penso que o outro é corresponde àquilo que o outro pensa que é. Há sempre a possibilidade de erro entre o que eu penso que o outro é e o que cada um pensa que é. Esse é o jogo das identidades que nos aprisiona e nos faz representantes da sociedade do enquadramento. $\mathrm{O}$ jogo das identidades diz dessas atribuições que fazemos no contato com as pessoas. Ao entrar em contato com o outro, eu sempre aposto na construção de uma identidade inteligível para esse outro, da mesma forma, que procuro sinais que me 
permitem ler e definir esse outro. Assim, todos nós atribuímos identidades aos outros e esses outros a nós mesmos. Mas Paulo encontra uma pessoa que transgredia as fronteiras das normas de gênero; ela vestia roupas que não eram socialmente próprias do seu sexo biológico, certamente gostava de ser chamada pelo pronome feminino: "ela se dizia professora, embora o nome fosse masculino" (PAULO, 2015. Informação verbal). Percebemos como as construções dicotômicas de gênero ancoradas no sexo biológico inferiorizam e marginalizam a profissional, seus direitos de se vestir como deseja e de ser chamada pelo pronome feminino são negados por uma busca de verdade que lhe impõe um modo fixo de viver o gênero. Nesse sentido, é possível perceber que

[...] as formas idealizadas dos gêneros geram hierarquia e exclusão. Os regimes de verdade estipulam que determinadas expressões relacionadas ao gênero são falsas, enquanto outras são verdadeiras e originais, condenando a uma morte em vida, exilando em si mesmo os sujeitos que não se ajustam às idealizações. (BENTO, 2011, p. 553)

A partir de situações como a descrita por Bento, a norma é reforçada, ao apontar os corpos que escapam de seus discursos de verdade como ilegítimos e essas experiências como aquelas que não devem ser vividas. A lógica estabelecida pelos regimes de verdade pressupõe um modelo universal de masculinidade e feminilidade e pretende criar corpos coerentes aos seus pressupostos. No entanto, para que esse projeto obtenha sucesso, é necessário que determinados discursos sejam proferidos constantemente, que os corpos sejam regulados, vigiados, disciplinados (FOUCAULT, 2014b). Por isso, em vez de perceber o gênero como restrito ao sexo biológico binário, importa entender como os corpos são atravessados por discursos diversos que constituem, marcam e constroem os sujeitos, perceber como eles surgem, que mecanismos são acionados para estabelecer padrões e normas.

Segundo o professor Paulo, os alunos e as alunas da escola também lidam como a professora, ancorados na determinação biológica, considerando que se trata de um homem e não de uma mulher. A relação talvez seja fortalecida exatamente porque encontra eco nos professores que não legitimam a professora trans como mulher. De qualquer forma, a reação dos alunos e alunas demonstra que já interiorizaram a norma, tanto que recusam a presença da profissional porque ela não corresponde ao que eles e 
elas consideram como 'correto', instaurando nesse espaço uma experiência da abjeção, de rejeição pela presença da professora que funciona como sentimento de horror àquele corpo que é dissidente. No regime da heteronormatividade, o rompimento com as normas de gênero parece ser mais hostilizado do que quando os indivíduos não correspondem à heterossexualidade. Dessa forma, até é admitido que se seja gay ou lésbica, desde que o corpo se aproxime dos ideais de masculinidade e feminilidade ancorados no biológico. Por ser um corpo estranho, que transita por esses ideais, esse corpo é rejeitado e temido naquele espaço.

\section{Considerações finais}

As narrativas trazidas aqui permitiram discutir a atuação das normas de gênero e da heteronormatividade em uma escola de Educação Básica, sobretudo pela presença de alunos e alunas que embaralham as noções de gênero e sexualidade das professoras e do professor. Alunos e alunas que escapam do enquadramento de gênero e sexualidade e que constroem novas demandas aos saberes que estão presentes na escola, que convocam as professoras e o professor a olharem para si, para seus saberes, para a escola e para o mundo. São cenas, fatos, percepções que foram narradas e dizem de um cotidiano escolar que subjetiva, constrói, produz tanto alunos e alunas, quanto professoras e professores. Dessa forma, ainda que não se tenha focado no currículo, como conteúdo das disciplinas, as vivências na escola permitiram perceber que o ato de aprender também ocorre a partir das mais diversas experiências do sujeito. A existência desses sujeitos que escapam dos enquadramentos de gênero e da hetenormatividade, por si só, traz a discussão para escola, visto que podemos pensar que os alunos e as alunas propõem um currículo, seja pelos seus interesses ou por suas existências. No ato de aprender, estão implícitas as conversas nos corredores, os olhares que são lançados e revisados, as perguntas que se fazem, reciprocamente, os espaços ocupados e os que são proibidos. Essas aprendizagens não se dão apenas de professor e professora para aluno e aluna, mas de aluno e aluna para professor e professora, entre tantas outras relações existentes na escola. 
Percebemos que o cotidiano escolar é marcado pelas “[...] normas que nunca escolhemos [...]" (BUTLER, 2016, p. 38), mas que capturam os sujeitos. Conforme mostrado nesta pesquisa, elas agem sobre os corpos que circulam no espaço escolar. Agem, a partir da escola, que, de uma maneira geral, adapta sua arquitetura, seu modo de funcionamento e sua rotina para produzir sujeitos normalizados, generificados, por meio de professores e professoras que se tornam agentes de normalização enquadrando os alunos e as alunas em lugares fixos e binários. Ocorre também por intermédio dos alunos e das alunas que se percebem dentro da norma e, mediante artifícios reguladores, promovem atitudes de violência com aqueles e aquelas que se distanciam do que está posto como próprio de homem e de mulher. A vigilância e a perseguição ao gênero é parte da escola.

Mas, quando se fala de cenas em que se percebe a norma, é possível mostrar também que existem corpos que não se conformam aos seus pressupostos, que questionam sua autoridade, que mexem com o que está posto e naturalizado. Sujeitos que se afirmam como homossexuais, lésbicas, que transitam por essas identidades e mostram que é possível escapar, transgredir e mostrar outras realidades no currículo escolar, evidenciando o caráter inventivo das masculinidades e feminilidades, que desafiam a heteronormatividade.

Dessa forma, a escola é marcada por poder/resistência, assim implicados, de modo que as intervenções em adequar cada corpo a um único gênero não são aceitas passivamente, sendo, antes, negociadas, resistidas e acontecem de maneira repetida, a partir de discursos que se reiteram e também são questionados. Assim, ainda que alguns alunos e algumas alunas ou professores e professoras deixem se moldar pelas normas, existem aqueles e aquelas que estão na contramão da normalização, isto é, fala-se também de professores e professoras e alunos e alunas que, mesmo se percebendo dentro dos modelos estabelecidos, reconhecem o caráter violento e compulsório da norma.

A problematização de cenas, considerando discurso como categoria teórica, permitiu perceber que as narrativas são atravessadas pelas construções nas quais as pessoas podem ser submetidas. Os discursos atravessavam as narrativas dos e das docentes, principalmente os discursos biológicos e religiosos, os quais colaboram para a 
produção de corpos generificados, para dicotomia e para processos de ensino/aprendizagem que concebem a heterossexualidade como norma e as demais formas de viver a sexualidade como anormais. Todavia, buscamos pensar a escola a partir das normas de gênero e da heteronormatividade inspirados em uma análise pós-crítica. Essa perspectiva de análise é uma possibilidade de perceber que, além dos muros físicos erguidos ao redor da escola, uma série de discursos hierarquizantes deixa, de fora do currículo escolar, corpos, gêneros e sexualidades que são ininteligíveis em seus processos e em suas demandas. Mais do que nunca, essas verdades precisam ser questionadas e tensionadas, sugerindo movimentos no currículo e a inserção, a permanência e as visibilidades de corpos abjetos, gêneros silenciados e sexualidades negadas.

Como a heteronormatividade atua seguindo a ideia sexo-gênero-sexualidade, os corpos que desobedecem a essa sequência provocam um embaralhamento nas concepções de gênero e sexualidade. Os sujeitos que são valorizados, postos como modelo e evidenciados são aqueles que seguem essa tríade. Todos os corpos são insistentemente investidos e regulados para se tornarem inteligíveis, ou seja, para corresponder a essas prescrições.

Os questionamentos levantados por esta pesquisa podem contribuir para que as escolas possam repensar suas práticas, refletir sobre os processos de subjetivação que têm desempenhado. As reiterações que ocorrem na escola, por vezes, impedem que os sujeitos se percebam como são capturados pelas normas. Olhar de outra perspectiva talvez seja um exercício de desconstrução e desnaturalização. Em tempos sombrios, como os vivenciados na atualidade, em que embates estão sendo realizados para enfraquecer os direitos das minorias, poder continuar discutindo normas de gênero e heteronormatividade no currículo escolar é uma forma de resistência. Pensamos em um futuro quando os corpos poderão transitar mais livremente, em uma educação sem estereótipos, preconceitos e violências, por isso, aposta-se em investimentos em pesquisas com essa temática, sugerindo outros tipos de leituras e outras ferramentas analíticas.

Ter uma vida mais vivível perpassa pela alegria e pelo prazer de aceitar aquele convite encontrado na blusa da professora com o qual se inicia este trabalho: aceitar o convite de não ser normal. Não se importar em se adequar a nada daquilo que enquadra, 
de não se conformar aos modelos impostos. Ter uma vida mais vivível é não ter as performances marcadas pela heteronormatividade, nem a sexualidade regulada por um padrão. Ter uma vida mais vivível é caminhar com liberdade, sem medo de violência por assumir um gênero, uma determinada sexualidade, sem medo de optar por transitar por essas e tantas outras demarcações que fixam a um lugar, a uma identidade. Ao questionar as normas de gênero e a heteronormatividade na escola, acredita-se ser possível a vida mais vivível nesse espaço.

\section{Referências}

ALINE. [Entrevista cedida a] Danilo Araujo de Oliveira, Aracaju (SE), 14 out. 2015.

ANDRADE, Paula Deporte de; COSTA, Marisa Vorraber. Usos e possibilidades do conceito de pedagogias culturais em estudos culturais em educação. Textura. Canoas (RS), v. 17, n. 34, p. 48-63, 2015. Disponível em:

http://www.periodicos.ulbra.br/index.php/txra/article/viewFile/1501/1140. Acesso em: 11 jan. 2021.

BENTO, Berenice. Na escola se aprende que a diferença faz a diferença. Estudos

Feministas, Florianópolis, p. 549-559, 2011. Disponível em:

https://www.scielo.br/scielo.php?pid=S0104-

026X2011000200016\&script=sci_abstract\&tlng=pt. Acesso em: 11 jan. 2021.

BRITZMAN, Deborah. O que é esta coisa chamada amor - identidade homossexual, educação e currículo. Trad. T. T. Silva, Educação e Realidade, Porto Alegre (RS), v. 21, n.1, p. 71-96, jan./jun. 1996. Disponível em:

https://seer.ufrgs.br/educacaoerealidade/article/view/71644. Acesso em: 11 jan. 2021.

BUTLER, Judith. Problemas de gênero: feminismo e subversão da identidade. Rio de Janeiro: Civilização Brasileira, 2003.

BUTLER, Judith. Regulações de gênero. Revista Cadernos Pagu, Campinas (SP), v. 42, p. 249-274, 2014. 
BUTLER, Judith. Corpos que ainda importam. In: COLLING, Leandro. (org.) Dissidências sexuais e de gênero. EDUFBA, Salvador, 2016.

CARVALHAR, Danielle Lameirinhas. Currículo da educação infantil: sexualidade e heternormatividade na produção de identidades. In: PARAÍSO, Marlucy. (org.). Pesquisas sobre currículos e culturas: temas, embates, problemas e possibilidades. Curitiba: CRV, 2010.

DANIELA. [Entrevista cedida a] Danilo Araujo de Oliveira, Aracaju (SE), 10 nov. 2015. DORNELLES, Priscila Gomes; DAL'IGNA, Maria Cláudia. Gênero, sexualidade e idade: tramas heteronormativas nas práticas pedagógicas da educação física escolar. Educação e Pesquisa, São Paulo, v. 41, p. 1585-1599, dez. 2015. Número especial. Disponível em: https://www.scielo.br/scielo.php?pid=S1517-

97022015001001585\&script=sci_abstract\&tlng=pt. Acesso em: 11 jan. 2021.

FISCHER, Rosa Maria Bueno. Foucault e a análise do discurso em educação. Cadernos de Pesquisa, São Paulo, n. 114, p. 197-223, 2001. Disponível em:

https://www.scielo.br/scielo.php?pid=S0100-

15742001000300009\&script=sci_abstract\&tlng=pt. Acesso em: 12 ago. 2019.

FOUCAULT. Michel. Os anormais. São Paulo: Martins Fontes, 2001.

FOUCAULT. Michel. Polêmica, política e problematizações. In: FOUCAULT. Michel. Ditos \& escritos V: ética, sexualidade, política. Rio de Janeiro: Forense Universitária, 2010. p. 225233.

FOUCAULT. Michel. Vigiar e punir: Nascimento da Prisão. 42 ed. Petrópolis: Vozes, $2014 a$.

FOUCAULT. Michel. Ditos e escritos IX: genealogia da ética, subjetividade e sexualidade. Rio de Janeiro: Forense Universitária, 2014b.

FOUCAULT. Michel. História da sexualidade I: a vontade de saber. São Paulo: Paz e Terra, 2014C.

JUNQUEIRA, Rogério Diniz. Currículo heteronormativo e cotidiano escolar homofóbico.

Espaço do Currículo, João Pessoa (PB), v. 2, n. 2, p. 208-230, mar. 2010. Disponível em: https://periodicos.ufpb.br/ojs2/index.php/rec/article/view/4281. Acesso em: 21 jan. 2021.

JUNQUEIRA, Rogério Diniz. A pedagogia do armário: heterossexismo e vigilância de gênero no cotidiano escolar. Revista Educação On-line PUC-Rio, Rio de Janeiro (RJ), n. 10, p. 64-83, 2012.

LOURO, Guacira Lopes. Pedagogias da sexualidade. In: LOURO, Guacira Lopes (org.). 0 corpo educado: pedagogias da sexualidade. Belo Horizonte: Autêntica, 2015. p. 7-34.

LOURO, Guacira Lopes. Uma sequência de atos. Revista Cult, São Paulo (SP), ano 19, n. 6, 2016. 
LOURO, Guacira Lopes. Gênero, sexualidade e educação: uma perspectiva pósestruturalista. Petrópolis: Vozes, 2003.

MISKOLCI, Richard. Teoria queer: um aprendizado pelas diferenças. Belo Horizonte: Autêntica, 2012.

OLIVEIRA, Danilo Araujo de. Normas de gênero e heteronormatividade em uma escola de educação básica em Aracaju (SE). 2017. 95 f. Dissertação (Pós-Graduação em Educação) Universidade Federal de Sergipe, São Cristóvão, 2017.

PAULO. [Entrevista cedida a] Danilo Araujo de Oliveira, Aracaju (SE), 18 out. 2015.

PARAISO, Marlucy Alves. Currículo, desejo e experiência. Revista Educação e Realidade, Porto Alegre: Editora da UFRGS, v. 34, n. 2, p. 277-293, maio/ago. 2009. Disponível em: https://seer.ufrgs.br/educacaoerealidade/article/view/9355. Acesso em: 11 jan. 2021.

REIS, Neilton; PINHO, Raquel. Gêneros não-binários: identidades, expressões e educação. Revista Reflexão e Ação, Santa Cruz do Sul, v. 24, n. 1, p. 7-25, jan./abr. 2016.

REIS, Cristina d'Ávila; PARAISO, Marlucy Alves. Normas de gênero em um currículo escolar: a produção dicotômica de corpos e posições de sujeito meninos-alunos. Estudos Feministas, Florianópolis (SC), v. 22, n. 1, p. 237-256, 2014. Disponível em: https://www.scielo.br/pdf/ref/v22n1/13.pdf. Acesso em: 11 jan. 2021.

RIBEIRO, Paula Regina Costa. Os corpos no espaço escolar: (re)configurações dos/as alunos/as anormais em tempos pós-modernos. In: FERRARI, Anderson; RIBEIRO, Claudia Maria; CASTRO, Roney Polato de; BARBORSA, Vanderlei. (orgs.). Corpo, gênero e sexualidade. Lavras: UFLA, 2014.

SCOTT, Joan. Gênero: uma categoria útil de análise histórica. Educação \& Realidade, Porto Alegre (RS), v. 20, n. 2, p. 71-99, 1995. Disponível em:

https://seer.ufrgs.br/index.php/educacaoerealidade/article/view/71721. Acesso em: 11 jan. 2021.

SILVA, Tomaz Tadeu. Documentos de identidade: uma introdução às teorias do currículo. Belo Horizonte: Autêntica, 1999.

Recebido em: 28/06/2020

Revisões requeridas: 11/01/2021

Aprovado em: 15/02/2021

Universidade do Estado de Santa Catarina - UDESC

Programa de Pós-Graduação em Educação - PPGE

Revista Linhas

Volume 22 - Número 48 - Ano 2021

revistalinhas@gmail.com 